\title{
Tratamiento cognitivo-conductual en un caso de fobia a la muerte
}

\author{
Mercedes Borda Mas, M. a Ángeles Pérez San Gregorio y M. ${ }^{a}$ Luisa Avargues Navarro \\ Universidad de Sevilla
}

\section{RESUMEN}

En este artículo se describe el tratamiento cognitivo-conductual llevado a cabo en un caso de fobia a la muerte, con un seguimiento de doce meses. La paciente es una mujer de 38 años. En la evaluación se utilizó el SCL-90-R, la $\mathrm{CL}-\mathrm{FODS}$ y las conductas-objetivo. El tratamiento se aplicó en 16 sesiones. Se utilizaron técnicas de control de la activación, técnicas de exposición (exposición en imaginación y en vivo e inundación en imaginación), así como técnicas de reestructuración cognitiva. Tras un año de seguimiento, se produjo una mejoría en la reducción de las conductas de evitación, en el control de los síntomas de ansiedad y de pensamientos y creencias relacionadas con la muerte, los muertos y el proceso de morir, así como en el malestar psicológico asociado a la vivencia de la muerte. Se comentan las implicaciones de este caso para la investigación y la práctica profesional.

Palabras clave: fobia a la muerte, tratamiento cognitivo-conductual, técnicas de exposición, eficacia, experimento de caso único.

\section{ABSTRACT}

In this paper, the cognitive-behavioural treatment applied in a case of death phobia monitored during twelve months is described. The patient is a 38 year old woman. In the evaluation, the SCL-90-R, the CL-FODS and objective behaviour were used. The treatment was applied in 16 sessions. Activation control, exposure techniques (exposure in imagination and in vivo, and flooding in imagination), as well as cognitive restructuring techniques were applied. After one year of monitoring, an improvement in the reduction of avoidance behaviour, in the control of anxiety symptoms, thoughts and beliefs related to death, the dead and the process of dying, as well as the psychological discomfort associated to the experience of death took place. The implications of this case are discussed for investigation and professional practice.

Keywords: Death phobia, cognitive behavioural treatment, exposure techniques, effectiveness, single-case experiment. 
La muerte y el proceso de morir es una experiencia común, que genera con frecuencia un cierto malestar, miedo y ansiedad. No obstante, en algunas personas, el malestar ocasionado llega a interferir en el funcionamiento cotidiano. En este sentido, como señalan Tomer, Eliason y Wong (2008), la muerte adquiere un significado personal y como tal, determina la forma en que vivimos.

La fobia a la muerte o tanatofobia se define como el temor acusado y persistente que es excesivo o irracional, desencadenado por la presencia o anticipación de objetos o situaciones específicas relacionadas con la muerte y el fallecimiento (DSM-IV-TR, APA, 2004). Del mismo modo que en el resto de los trastornos fóbicos, la exposición a situaciones o estímulos tanatofóbicos provoca una respuesta inmediata de ansiedad, en forma de una crisis de ansiedad situacional o más o menos relacionada con una situación determinada (por ejemplo, funerales, ver ataúdes, conversaciones de fallecimientos, etc.). Por ello, es frecuente que estas situaciones se eviten o se soporten a costa de una intensa ansiedad o malestar.

En psicología clínica, cuando se habla de la muerte, la ansiedad ante la muerte o el miedo a la muerte, en general, se hace referencia a aquel periodo de la vida más próximo al final de la existencia (Kübler-Ross, 2009). En este sentido, el ámbito de mayor atención psicológica y emocional se centra en personas que se encuentran en el proceso del final de la vida, especialmente personas ancianas o aquellas que padecen una enfermedad incurable (Bayés, 2006).

En ocasiones, el proceso de la aceptación de la muerte y el proceso de morir no se limita al final de la vida. Existen personas con un modo de afrontamiento diferente. Cuanto más luchan para esquivar la muerte inevitable, cuanto más tratan de negarla, más difícil les resulta llegar a la fase final de la vida en paz, con aceptación. A lo largo de su vida, no pueden admitirla. Les provoca rechazo y disgusto. Luchan hasta el final $y$, a menudo, desperdician la oportunidad de aceptar la muerte con un desenlace final.

Las personas con fobia a la muerte, más allá del proceso del final de la vida, sufren a lo largo de su existencia un temor que les limita en el manejo de su vida cotidiana. Cada día, la idea de dejar de existir propia y ajena se convierte en una fuente permanente de estrés. El miedo a no sentir nada, ni ver, ni estar con gente, ni oir, nada... y, sobre todo, pudrirse en una tumba o ser desintegrada, les aterroriza. Se produce asimismo un miedo al deterioro reflejado en el cuerpo, debido al paso de los años, con indicios relacionados con la proximidad de la muerte (por ejemplo, el pelo canoso, las arrugas en la piel o el propio olor del cuerpo), e incluso se produce un temor a oír o hablar sobre padecimientos que suponen un deterioro del organismo (por ejemplo, manchas en la piel) y, por tanto, signos de ausencia de vida. Para estas personas, aunque la muerte se corresponda con un instante y sólo dure una brevedad, en cambio, la agonía del día a día por el temor a la ausencia de vida dura toda una existencia.

Más allá del trabajo de Avia (1992), la literatura sobre tratamientos psicológicos eficaces para la fobia a la muerte en nuestro país es prácticamente inexistente. Por ello, el objetivo de este trabajo es mostrar la eficacia de la 
terapia cognitivo-conductual, tras un año de seguimiento, mediante el estudio de un caso único. La técnica básica que se utilizó fue la exposición.

\section{Identificación del paciente y motivo de consulta}

La paciente es una mujer de 38 años de edad. Está casada desde los 22 años y refiere estar satisfecha con su matrimonio. Tiene una hija de 14 años. Profesionalmente, trabaja en el mismo organismo público desde los 18 años, tras haber cursado los estudios superiores y prepararse para opositar. Se considera responsable y comprometida, pues le gusta su trabajo. Progresivamente, se ha ido promocionando $y$, actualmente, desempeña un cargo de cierta responsabilidad.

Procede de una familia de cinco hermanos. Ella es la mayor. A continuación, le siguen dos varones y en último lugar, dos chicas gemelas. De su infancia y adolescencia guarda buenos recuerdos, en general. Destaca el hecho de que, aunque le gustaban los juegos de niñas, lo hacía más a los de los chicos con sus hermanos y su padre (coches, fútbol, etc.).

Su madre le dedicaba menos atención a esta faceta, pues padecía problemas renales y eso le limitaba, en parte, la vida y los cuidados a los niños. Durante el embarazo de las gemelas, tuvo que ser intervenida quirúrgicamente de urgencia por cálculos en un riñón, con el consiguiente riesgo para su salud y vida, así como la de las niñas. La operación resultó exitosa, pero hasta el nacimiento, en la casa, se vivió ese intervalo de tiempo con preocupación.
La paciente tenía 9 años y fue, en ese momento, cuando se hizo consciente por primera vez de la idea de la muerte: «su madre podía morir... y sus hermanas podían morir... después de nacer... o antes». Esta idea le rondó por la cabeza durante algún tiempo (por ejemplo, en forma de «podemos desaparecer», "a dónde nos vamos», "qué vamos a hacer los demás») pero, poco a poco, se fue disipando, sin querer preguntar ni hablar del tema en casa. Ahora atribuye este periodo de tiempo como el primer momento, clave sobre la muerte y su futuro miedo.

Señala que, afortunadamente, a lo largo de estos años contaron con una buena salud ella y su familia. Salvo los cuidados y los seguimientos de la enfermedad de su madre (que no se vivía en casa con angustia ni preocupación), las visitas a los médicos por diferentes problemas de salud, según comenta, transcurrieron con relativa normalidad, de tal manera que, después de aquel primer momento, ya no recuerda haber dedicado tiempo a pensar en la muerte hasta los 16 años, tras el fallecimiento de un familiar anciano. Al entrar en la sala del domicilio en la que se encontraba el familiar, ese instante se le quedó grabado, pues le produjo un fuerte impacto. Apenas había luz en la habitación, y daba sensación de frialdad, de vacío («como el fondo de una cueva oscura», describía ella). No sabe por qué, pero al acercarse al féretro, la postura del difunto, el color de la cara, la deformación de las facciones, etc., no pudo controlarse. Como iba acompañada, sintió un ligero empujón en la espalda (para que avanzara hacia la sala), pero le temblaban las piernas, sintió que se atragantaba y no po- 
día tragar la saliva. Quería escapar, retroceder, pero no tuvo valor. Sintió un sudor frío que le recorría el cuerpo. En ese instante, alguien (estaba tan aturdida que no recuerda quién fue) le preguntó si se encontraba bien, pues estaba muy pálida. Sólo fue capaz de decir «sí... sí, estoy bien», pero estaba tan atemorizada diciéndose "qué horror .... está muerto muerto», «qué muerto está» que esa visión no se le ha olvidado nunca. A la vez, sentía angustia, tristeza, terror e impotencia. Este momento tan desafortunado no se le ha borrado de la mente y se ha ido repitiendo esta visión a lo largo de su vida, recordándolo en ocasiones cuando se ha tenido que enfrentar a situaciones parecidas.

A partir de este día, con cierta frecuencia, se cuestionaba a sí misma «¿y ahora qué?» « $a$ dónde vamos?» «iqué horror!» «¿y si no estamos del todo muertos?» «que te entierren o te incineren...». Pensamientos similares a estos le generan una gran inquietud motora, se sacude el cuerpo (en un intento de sentirse viva) y, de inmediato, cambia de actividad para quitarse esa idea de la cabeza. En la medida que puede, evita el contacto o la aproximación a todo aquello relacionado con la muerte (como por ejemplo, visitar a enfermos terminales o tocar a personas ancianas) y los muertos (como por ejemplo, acudir al cementerio o ver ataúdes). Ante cualquier situación tanatofóbica, reacciona con sudoración, temblor en todo el cuerpo, palpitaciones, mayor vasoconstricción en las manos y en la cabeza, así como tensión muscular en la parte de la nuca y la cara. Por otro lado, también evita participar en conversaciones relacionadas con el tema de la muerte ("¿Qué hay más allá de la muerte? No sé... me horroriza pensarlo»), no saca este tema de conversación («No quiero hablar de ese tema... me niego a hablar de la muerte... no quiero saber que hay después... cuando llegue la hora me moriré y punto. Pero no lo acepto, me rebelo contra ella y mientras pueda. Lucharé con todas mis fuerzas... contra la mía y la de los demás -allegados-»). En general, le preocupa y/o le impresiona envejecer, morir y qué hay después de la muerte.

Se considera una persona sin complicaciones serias de salud. No ha recibido ningún tipo de tratamiento médico o psicológico por este problema, si bien, ha sido el médico de cabecera quien le ha asesorado y sugerido acudir a un especialista para tratar esta dificultad.

Aparte de la tanatofobia, motivo que le trae a la consulta, no ha padecido ningún trastorno psicológico de importancia. Se ve a sí misma como una persona sociable, con buenos amigos, interesada por su familia y su trabajo. No consume alcohol ni tabaco y sus actividades favoritas son: leer, pasear y viajar.

Durante todo el proceso, se siguieron las recomendaciones recogidas por Del Río (2005) acerca de los aspectos éticos en psicología clínica. Para la redacción del artículo se han seguido las directrices de Virués-Ortega y Moreno-Rodríguez (2008).

\section{Estrategias de evaluación}

En la evaluación se utilizaron diversas estrategias.

a) En primer lugar, a partir de la entrevista inicial, se recogió información de algunos parámetros o variables útiles para el profesional, indicadores de adherencia al tratamiento por parte de la paciente (Ver Tabla 1). 
Tabla 1

Puntuaciones en algunos parámetros de interés clínico recogidos en la entrevista inicial

\begin{tabular}{lc}
\hline \multicolumn{1}{c}{ Variables } & Puntuación o respuesta \\
\hline $\begin{array}{l}\text { Percepción de autocontrol de la fobia } \\
(0=\text { nada, } 5=\text { muchísimo })\end{array}$ & 1 \\
$\begin{array}{l}\text { Estrategia actual de afrontamiento } \\
\text { Nivel de interferencia del problema en su vida } \\
(0=\text { nada, } 5=\text { muchísimo })\end{array}$ & Evitación \\
$\begin{array}{l}\text { Nivel de compromiso con el tratamiento } \\
(0=\text { nada, } 5=\text { totalmente })\end{array}$ & 5 \\
Nivel de motivación $(0=$ nada, $5=$ muy motivada) & 3 \\
\hline
\end{tabular}

Tras obtener dicha información, se le formuló la pregunta siguiente:

-Terapeuta (T): ¿Qué esperas conseguir con el tratamiento?

-Paciente $(P)$ : Hacer más llevadero este sufrimiento, pero no quiero cambiar mi idea, no quiero aceptar la muerte.

b) En segundo lugar, se procedió a la valoración general de la posible psicopatología existente en la paciente. Se utilizó la versión en español del Cuestionario de Evaluación de Síntomas / Symptoms Check List - SCL-90-R (Derogatis \& Cleary, 1977), constituido por 90 items agrupados en nueve dimensiones de síntomas primarios: somatización, obsesión-compulsión, sensibilidad interpersonal, depresión, ansiedad, hostilidad, ansiedad fóbica, ideación paranoide y psicoticismo. Presenta cinco alternativas de respuesta en una escala de tipo Likert ( 0 = nada, en absoluto; 4 = de forma extrema). De los tres niveles de información, se han empleado la puntuación del nivel dimensional, constituido por la puntuación de cada dimensión. Los coeficientes de fiabilidad de la versión española del SCL-90-R, analizados en una muestra de participantes clínicos han sido satisfactorios (Robles, Andreu , \& Peña, 2002), éstos han oscilado entre 0,69 en la escala de ansiedad fóbica y 0,85 en la de somatización y son equiparables a los que otros estudios han revelado (González de Rivera, De las Cuevas, Rodríguez , \& Rodríguez, 2002).

Para determinar la sintomatología, como valores de referencia se tomaron en consideración las puntuaciones medias dadas por los participantes en el estudio recientemente llevado a cabo en nuestro país por Bravo de Medina, Echeburúa y Aizpiri (2010). El grupo clínico estaba constituido 140 pacientes en su mayoría con trastornos de ansiedad y trastornos del estado de ánimo y el grupo sano, también constituido 140 personas sanas, sin patología mental, seleccionada entre la población que no estaba en tratamiento psiquiátrico ni psicológico.

c) En tercer lugar, se procedió a la valoración de los síntomas o manifestaciones específicas de la fobia a la muerte. Ante la inexistencia de un instrumento específico validado para este tipo de fobia, se recurrió a la medida de 
la ansiedad ante la muerte a través de un instrumento adaptado a la población española: Escala de Ansiedad ante la Muerte / Collet-Lester Fear of Death Scale (CL-FODS) (Lester, 1990; Templer, 1970), de Tomás-Sábado, Limonero y Abdel-Khalek (2007). Evalúa el grado de preocupación o ansiedad experimentado ante diferentes aspectos relacionados con la muerte y el proceso de morir. Consta de 28 items, con siete ítems en cada una de las cuatro subescalas: miedo en relación a la propia muerte, al propio proceso de morir, a la muerte de otros y al proceso de morir de otros. Presenta cinco alternativas de respuesta en una escala de tipo Likert ( 1 =nada; $5=$ mucho). La puntuación total en cada subescala oscila entre 7 y 35 puntos. La CL-FODS no dispone de punto de corte. Se considera que a mayor puntuación, mayor nivel de ansiedad ante la muerte, si bien no es infrecuente encontrar puntuaciones entorno a los 80-90 puntos en la población general. Los coeficientes de fiabilidad para cada una de las subescalas de la versión española son satisfactorios, oscilando entre 0,79 y 0,89. La fiabilidad test-retest con un intervalo de dos semanas oscila entre 0,72 y 0,82 , indicando que la CLFODS posee una buena consistencia interna y estabilidad temporal.

Como medida de referencia, se tomaron en consideración las puntuaciones medias obtenidas en el estudio de adaptación española de la CL-FODS Ilevada a cabo en nuestro país por Tomás-Sábado et al. (2007). La muestra estaba constituida por 281 participantes vinculados al ámbito de la salud. Las puntuaciones medias quedan recogidas en la Tabla 5. d) En cuarto lugar, se realizó una observación directa durante la sesión. Como puede verse en la Tabla 2, la evaluación consistió en registrar las reacciones que iba experimentando la paciente durante el desarrollo del diálogo establecido entre terapeuta y paciente, basado en un pensamiento de contenido tanatofóbico, así como el malestar que le generaba permanecer conversando sobre el tema de la muerte. El objetivo era enseñar a detectar los síntomas o perfil específico de respuesta, con la finalidad de utilizar esta sintomatología en el entrenamiento, aprendizaje y manejo de las técnicas durante el tratamiento. Para ello, tras acuerdo previo, se seleccionó el item no 5 de la CL-FODS. El tiempo aproximado de esta secuencia fue de dos minutos.

e) Finalmente, se fijaron seis conductas-objetivo, conductas específicas que actualmente le generaban dificultad y que, por tanto, tendían a ser evitadas. Se seleccionaban aquellas que la paciente mostraba interés por llevar a cabo tras el tratamiento. Posteriormente, se utilizarían como material de las sesiones de tratamiento. Se puntuaron dos medidas: grado de dificultad ( $0=$ nada a $10=$ mucho) y la frecuencia de evitación ( 0 = nunca a $5=$ siempre) (ver Tabla 6).

Los datos referidos al subapartado a) entrevista inicial, b) SCL-90 y d) observación directa, se recogieron exclusivamente en la evaluación pretratamiento, como paso previo al inicio del tratamiento con la finalidad de conocer con mayor precisión las características de la paciente. La CL-FODS se midió en la evaluación pretratamiento y en el seguimiento del año. En cambio, la valoración de las conductas objeti- 
Tabla 2

Reacciones observadas en la paciente y nivel de malestar en la observación directa realizada en la evaluación pretratamiento

\begin{tabular}{|c|c|c|c|}
\hline & ¿Cómo será el estar muerto? & Reacción de la paciente & $\begin{array}{c}\text { Malestar } \\
(0=\text { nada }, 10=\text { muchísimo })\end{array}$ \\
\hline I & $\begin{array}{l}\text { T: Es cierto. Las personas se suelen hacer } \\
\text { esta pregunta, pero nadie sabe a ciencia } \\
\text { cierta cómo será. ¿Sabes tú alguna opi- } \\
\text { nión de la gente? } \\
\text { P: No lo sé. Como no suelo hablar de este } \\
\text { tema ... no lo sé. } \\
\text { T: De acuerdo. Pero, tal vez, puedas imagi- } \\
\text { nar, recordar o intuir incluso lo que pue- } \\
\text { den opinar. } \\
\text { P: Pues eso... Que no hay nada. No respi- } \\
\text { ras... no oyes... todo oscuro. } \\
\text { (Se detiene unos instantes el diálogo) }\end{array}$ & $\begin{array}{l}\text { Nerviosismo e inquietud. } \\
\text { Sudoración, taquicardia, tem- } \\
\text { blores en los brazos y en la } \\
\text { cabeza (haciendo gestos de } \\
\text { negación). Dificultad para res- } \\
\text { pirar. } \\
\text { Pensamientos anticipatorios } \\
\text { de miedo, ira, rechazo. } \\
\text { Se siente capaz de controlar } \\
\text { los síntomas }\end{array}$ & $6-8$ \\
\hline II & $\begin{array}{l}\text { T: Así es. Pero eso es nada más fallecer } \\
\text { ¿no? o ¿ya para siempre?. } \\
\text { P: Uf, que sé yo. No quiero ni pensarlo... } \\
\text { T: Intenta pensarlo. } \\
\text { P: (se queda pensativa) Será para siem- } \\
\text { pre... ¿para siempre? ¿qué siempre? Si ya } \\
\text { muerto... no hay tiempo. }\end{array}$ & $\begin{array}{l}\text { Nerviosismo e inquietud. } \\
\text { Sudoración, taquicardia, tem- } \\
\text { blores en los brazos y en la ca- } \\
\text { beza. Dificultad para respirar. } \\
\text { Mayor presión en la cabeza } \\
\text { Ira, rechazo. } \\
\text { Se siente capaz de controlar } \\
\text { los síntomas, con dificultad. }\end{array}$ & $8-9$ \\
\hline III & $\begin{array}{l}\text { T: ¿Eso es lo que opina otra gente o lo que } \\
\text { opinas tú?. } \\
\text { P: Todos ¿no? Cuando falleces se acaba el } \\
\text { tiempo. } \\
\text { T: Bueno, tal vez no todos opinen lo mis- } \\
\text { mo ¿tú que crees? } \\
\text { P: (Rápidamente) Que se acaba todo. Que } \\
\text { ya dejas de vivir y además, te destruyen, } \\
\text { te desintegras. No hay más que pensar. } \\
\text { (Después de unos instantes en silencio, } \\
\text { con la mirada ausente) }\end{array}$ & $\begin{array}{l}\text { Más nerviosa e inquieta. } \\
\text { Sudoración, taquicardia, tem- } \\
\text { blores en los brazos y en la ca- } \\
\text { beza. Dificultad para respirar. } \\
\text { Mayor presión en la cabeza. } \\
\text { Tensión en la cara, arrugán- } \\
\text { dola. } \\
\text { Rechazo } \\
\text { Se siente capaz de controlar } \\
\text { los síntomas, con dificultad. }\end{array}$ & 9 \\
\hline IV & $\begin{array}{l}\text { P: (Levantando la vista) No voy a aceptar } \\
\text { la muerte. } \\
\text { T: Eso me has comentado. Pero algo sí } \\
\text { que quieres conseguir ¿no es así? } \\
\text { P: Sí, no pasarlo tan mal con este tema. No } \\
\text { sufrir tanta angustia ni descontrolarme } \\
\text { tanto. Pero seguiré luchando con todas } \\
\text { mis fuerzas mientras pueda para no irme. }\end{array}$ & $\begin{array}{l}\text { Finaliza el diálogo. } \\
\text { Inspiración profunda, para re- } \\
\text { lajarse. }\end{array}$ & 8 \\
\hline
\end{tabular}

Nota. $\mathrm{T}=$ terapeuta; $\mathrm{P}=$ paciente. 
vo se realizó en diferentes momentos: pretratamiento, postratamiento, seguimiento al mes, a los seis y doce meses.

\section{Formulación clínica del caso}

En esta paciente, el inicio del problema se sitúa en la infancia tras la vivencia familiar de una experiencia vital en la que estaba presente la amenaza de la pérdida de una vida (madre y/o hermana/s), si bien no es hasta la adolescencia cuando se produce la aparición de conductas fóbicas de evitación a nivel conductual, y además a nivel cognitivo al tener ante sí el cadáver de un familiar.

Desde que comenzó con estas conductas hasta el momento antes del tratamiento, el miedo ha persistido en el tiempo y su situación, en ocasiones, se convierte en una fuente de gran malestar. Esto puede ser debido a que la muerte está relacionada con una gran multitud de situaciones de la vida cotidiana, de las que intenta escapar, quedando reforzada negativamente dicha conducta por el temor a contactar con la muerte. Por otro lado, a pesar de tener que hacer frente en ocasiones -a situaciones tanatofóbicas- sin ningún interés por su parte, el malestar no desaparece al verse alimentado por el temor a lo que conlleva en sí misma la muerte (pérdida de la vida, despedida de los seres queridos, autodestrucción, etc.). El carácter existencial, más allá de la irracionalidad de otras fobias, la convierte en sustancialmente diferente.

Estas manifestaciones clínicas, junto con la sintomatología de ansiedad en forma de crisis con síntomas de activación general, han contribuido al mantenimiento del problema. En esta paciente, como consecuencia del miedo a la muerte, hasta el momento del tratamiento se percibe con ausencia de control sobre su problema y opta por rechazar todo aquello relacionado con la muerte.

\section{Diseño del estudio}

El trabajo presentado se incluye dentro de los estudios experimentales en los que un solo individuo es el propio control. Se denomina experimento de caso único. La variante utilizada responde al diseño sin retirada $A B$, por ser un tipo de diseño en el que no se puede retirar el tratamiento (Montero \& León, 2007).

\section{Tratamiento}

El tratamiento realizado, desde la perspectiva cognitivo-conductual, se centró en los tres niveles del triple sistema de respuesta: a nivel fisiológico, cognitivo y conductual.

Los objetivos terapéuticos y las técnicas seleccionadas fueron las siguientes:

a) Controlar los síntomas de ansiedad:

- a nivel fisiológico, en general y en particular ante situaciones relacionadas con la muerte y los muertos

- y a nivel cognitivo, ante pensamientos relacionados con la muerte: respiración tranquilizadora y relajación muscular progresiva.

b) Reducir las conductas de evitación:

- real o en vivo, mediante el enfrentamiento ante situaciones relacionadas con la muerte y los muertos: exposición gradual en vivo.

- y cognitiva, de los pensamientos relacionados con la muerte, los muertos y el 
proceso de morir: inundación en imaginación.

c) Reducir el nivel de malestar emocional asociado con la vivencia de la muerte y el proceso de morir: reestructuración cognitiva (mediante diálogo socrático y exposición en imaginación).

El diario de sesiones, en el que se incluye el número y el contenido de las mismas, se recoge en la Tabla 3. La duración del tratamiento fue de cinco meses. Las doce primeras sesiones se llevaron a cabo con una periodicidad semanal, y de la sesión doce a la dieciséis la periodicidad fue quincenal. La duración de cada sesión se estimó en torno a 60-70 minutos.

\section{Aplicación del tratamiento}

En la primera sesión de tratamiento se hizo hincapié en el aprendizaje de técnicas de control de activación:

a) Procedimiento de entrenamiento y aplicación de la respiración tranquilizadora. Empleada para conseguir un estado de relajación de forma rápida. Se siguió el esquema de la técnica de Foa y Wilson (2001).

En general, las instrucciones de los ejercicios son:

$1^{\text {a }}$ Realizar una inspiración profunda.

$2^{\text {a }}$ Retener durante un periodo de entre 5 y 10 sgs. el aire.

$3^{a}$ Posteriormente, expulsar lentamente el aire.

\section{Tabla 3}

Diario de sesiones durante el tratamiento

\begin{tabular}{|c|c|c|}
\hline Sesión & Pasos & Contenido de las sesiones \\
\hline \multirow[t]{3}{*}{$1^{\mathrm{a}}$} & I & $\begin{array}{l}\text { Recordatorio de la información sobre diversos conceptos (muerte, muer- } \\
\text { tos, proceso de morir, etapas de la vida, emociones y reacciones o estrate- } \\
\text { gias de afrontamiento ante la muerte, etc.). }\end{array}$ \\
\hline & II & $\begin{array}{l}\text { Explicación y entrenamiento de las técnicas: Respiración tranquilizadora y } \\
\text { relajación muscular progresiva. }\end{array}$ \\
\hline & III & Tareas para casa. \\
\hline \multirow[t]{5}{*}{$2^{\mathrm{a}-15^{\mathrm{a}}}$} & I & Comentario sobre las dificultades surgidas en las tareas entre sesiones. \\
\hline & II & $\begin{array}{l}\text { Repaso de los ejercicios de entrenamiento a utilizar durante el enfrenta- } \\
\text { miento con el contexto tanatológico. }\end{array}$ \\
\hline & III & Explicación de otras técnicas: \\
\hline & & $\begin{array}{l}\text { - Exposición en vivo a las conductas-objetivo definidas: cumplimenta- } \\
\text { ción del registro de exposiciones, autoinstrucciones, coterapeuta. } \\
\text { - Inundación en imaginación ante los pensamientos señalados. } \\
\text { - Diálogo Socrático y Exposición en imaginación. }\end{array}$ \\
\hline & IV & Preparación de las tareas entre sesiones. \\
\hline \multirow[t]{4}{*}{$16^{\mathrm{a}}$} & I & Comentario sobre las dificultades surgidas en las tareas entre sesiones. \\
\hline & II & Repaso de las técnicas utilizadas y prevención de recaídas. \\
\hline & III & Valoración global del tratamiento. \\
\hline & IV & Preparación de tareas a medio y largo plazo. \\
\hline
\end{tabular}


b) Procedimiento de entrenamiento y aplicación de la relajación muscular progresiva. Empleada para alcanzar niveles profundos de relajación muscular. Se siguió el esquema de la técnica Jacobson (1939).

En general, las instrucciones de los ejercicios son:

$1^{\text {a }}$ Tensar el grupo muscular correspondiente.

$2^{\text {a }}$ Focalizar la atención en el grupo muscular en tensión.

$3^{a}$ Relajar el grupo muscular correspondiente.

$4^{\text {a }}$ Focalizar la atención en el grupo muscular en relajación.

Tras ejercicios de tensión/distensión en los 16 grupos musculares, disfrutar del estado de relajación.

A partir de la segunda sesión, se introdujo el aprendizaje de las técnicas conductuales y cognitivo-conductuales, en concreto, la exposición y la reestructuración cognitiva.

c) Procedimiento de entrenamiento y aplicación de la exposición en vivo, con la finalidad de reducir las conductas de evitación real.

En la sesión inicial se llevó a cabo:

- La selección de la conducta-objetivo para trabajar.

- La elaboración de la/s tarea/s a realizar en la sesión:
I. Lugar o situación concreta.

II. Definición de los parámetros: duración y/o frecuencia.

III. Ayuda: con coterapeuta o sola.

IV. Empleo de estrategias complementarias: autoinstrucciones, respiraciones, distracción, quitar la vista, etc.

A modo de ejemplo, se presenta la propuesta de una tarea a realizar sobre la conducta objetivo seleccionada: Mantener la vista ante una persona fallecida (cadáver) observada en la TVo en una revista (Tabla 4).

- La utilización de retroalimentación o feedback.

- La elaboración de las tareas para realizar hasta la próxima sesión.

Desde la sesión siguiente de tratamiento, en adelante, se procedió a:

- Comentar las dificultades surgidas en la exposición.

- Seleccionar la/s conducta/s-objetivo para trabajar. Por ejemplo, en esta sesión se seleccionó Mantener la vista ante una persona fallecida (cadáver) observada en la TV o en una revista (grado de dificultad $=8$ ) y Ver películas con la temática de la muerte (grado de dificul$\operatorname{tad}=8,5)$.

Tabla 4

Ejemplo de propuesta de tarea a realizar

\begin{tabular}{llccr}
\hline Día y hora & Tarea & Tiempo Noveces & Sola/acompañada & Estrategias a utilizar \\
\hline $\begin{array}{l}\text { 20/09 } \\
\text { En la sesión }\end{array}$ & $\begin{array}{l}\text { Abrir la página de } \\
\text { una revista en la que } \\
\text { se observe un funeral }\end{array}$ & $\begin{array}{c}2-3 \text { mins } \\
\text { veces }\end{array}$ & $\begin{array}{c}\text { Acompañada } \\
\text { del terapeuta }\end{array}$ & $\begin{array}{r}\text { Respiraciones } \\
\text { Autoinstrucciones: }\end{array}$ \\
& & & "Puedo controlarme», \\
& & & "Voy a tranquilizarme» \\
\hline
\end{tabular}


Elaboración de la/s tarea/s a realizar en la sesión:

- Recordatorio de las estrategias complementarias: autoinstrucciones, respiraciones, distracción, quitar la vista, etc.

- Preparación de estrategias para momentos de riesgo (relacionados con el malestar emocional de ira o rechazo): empleo de la exposición en imaginación.

- Utilización de la retroalimentación o feedback.

- Elaboración de las tareas para realizar hasta la próxima sesión.

d) Procedimiento de entrenamiento y aplicación de la inundación en imaginación, con la finalidad de reducir la evitación de pensamientos relacionados con la muerte, los muertos y el proceso de morir:

- Se llevó a cabo mediante la narración de textos que generaban niveles elevados de preocupación y ansiedad ante la muerte (por ejemplo: cómo será estar muerto). Para facilitar el procedimiento a la hora de disponer de material para la narración, se recurrió a la valoración de los ítems de la CL-FODS, de tal manera que, a partir de la graduación, se fueron seleccionando. No obstante, tal y como puede verse en la Tabla 5, el rango osciló entre 3 y 5 puntos, con una tendencia a evitar el pensamiento de siempre-casi siempre.

- Los textos eran elaborados conjuntamente entre el terapeuta y la paciente durante la sesión.

- Ocupaban aproximadamente una cara de un folio (un minuto y me- dio o dos minutos, más o menos, de lectura).

- A continuación, tras relajar a la paciente, se le exponía en imaginación al pensamiento, creencia, etc., dando lectura al texto de forma lenta, cuyo contenido era conocido en todo momento por ella previamente.

- La presentación se intercalaba con instantes de silencio, para facilitar el autocontrol y, por tanto, la habituación al contenido del mensaje.

- Tras finalizar la primera lectura, se repetía otras tres o cuatro veces el texto, antes de concluir. Tiempo aproximado invertido: entre 10 - 15 minutos.

A modo de ejemplo, la narración del item 13, Tener que estar con alguien que se está muriendo fue: Cuando estoy junto a alguien que se está muriendo el olor... lo primero... voy notando el olor en la habitación se respira a muerto... aún antes de estar muerto, ya estoy oliendo a muerto... Cuando estoy en su casa, en su cama me impresiona menos porque no tiene aparatos ni otras cosas colocadas en el cuerpo... Pero está ingresada... estoy entrando en su habitación... le veo entre tubos... aparatos... detrás está ella... Me voy poniendo más nerviosa, muy inquieta y comienzo a sudar... Su aspecto está encogida... arrugada... pálida... da sensación de frío, de estar apagándose. Me entristezco al verla... a la vez, siento una fuerza interna que me lleva a rebelarme contra lo que estoy viendo... Siento yo angustia por ella... por verla aparentemente tranquila... o resignada... veo su mirada ¿qué querrá decir? 
e) Por último, se describe el procedimiento de entrenamiento y aplicación de la exposición en imaginación.

- Se llevó a cabo para entrenar a la paciente a facilitar el cambio de emocio- nes negativas intensas en imaginación por otras que generaran menor malestar tanto en las situaciones como ante los propios pensamientos y creencias.

- Se le pedía que, tras estar lo más rela-

Tabla 5

Ítems de la escala CL-FODS con puntuaciones más elevadas en el pretratamiento utilizadas para la inundación en imaginación

"Me produce mucha preocupación o ansiedad"... $\quad \begin{gathered}\text { Grado de malestar } \\ (0=\text { nada a } 10=\text { mucho })\end{gathered}$
Frecuencia de evitación del pensamiento $(0=$ nunca a 5 = siempre $)$

1. La total soledad de la muerte. 5

2. Todas las cosas que perderé al morir.

3. Cómo será el estar muerto.

10

4. No poder pensar ni experimentar nada nunca más.

5. La desintegración del cuerpo después de morir.

6. La degeneración física que supone el proceso de morir.

7. La degeneración mental que supone el proceso de morir.

8. El dolor que comporta el proceso de morir.

9. La pérdida de facultades durante el proceso de morir.

10. La pérdida de una persona querida.

11. Tener que ver su cadáver.

12. No poder comunicarme nunca más con ella.

13. Tener que estar con alguien que se está muriendo.

14. Tener que estar con alguien que quiere hablar de la muerte contigo.

15. Observar la degeneración física de su cuerpo.

16. Asistir al deterioro de sus facultades mentales.

17. Ser consciente de que algún riencia. 
jada posible, se imaginase vívidamente (con todo lujo de detalle) una situación específica de alto contenido emocional negativo (por ejemplo: cómo será estar muerto).

- Cuando lo estuviera imaginando con claridad, se le señalaba que identificara las emociones negativas (angustia, depresión, ira...) que estaba experimentando.

- A continuación, se le decía que tratara de cambiar esas emociones negativas por otras más adaptativas (tristeza, malestar...) utilizando para ello un pensamiento de menor carga emocional.

A modo de ejemplo, se presenta cómo se trabajó el pensamiento generador de emociones negativas: No podré pensar ni experimentar nada nunca más.

- Se le pedía que, tras estar lo más relajada posible, se imaginase vívidamente (con todo lujo de detalle) una situación específica de alto contenido emocional negativo (por ejemplo: cómo será estar muerto).

- Cuando lo estuviera imaginando con claridad, se le señalaba que identificara las emociones negativas (angustia, depresión, ira...) que estaba experimentando.

- A continuación, se le decía que tratara de cambiar esas emociones negativas por otras más adaptativas (tristeza, malestar...) utilizando para ello un pensamiento de menor carga emocional.

A modo de ejemplo, se presenta cómo se trabajó el pensamiento generador de emocio- nes negativas: No podré pensar ni experimentar nada nunca más.

-T: Imagina un día cualquiera, que estás tranquila... y, de pronto, se te pasa por la cabeza que cuando fallezcas "no podrás pensar ni experimentar nada nunca más".

-P: De acuerdo.

-T: Cuando lo imagines, concéntrate en sentir lo más intensamente que puedas esta idea «no podré pensar ni experimentar nada nunca más».

-P: (tras unos instantes) Es muy injusto, no puedo soportar esa idea. Me da mucha rabia todo lo que voy a perder. En verdad, me niego a querer incluso pensar en ello.

-T: Inténtalo de nuevo. Imagínate pensando esa idea y percibe cómo te estás sintiendo, cuánto estás sufriendo. Después de unos instantes, sólo entonces, procura pensar en algo que te haga sufrir menos, pero no lo evites. Enfréntate.

$-\mathrm{T}$ : ¿Lo estamos consiguiendo?

-P: No, no es fácil. Cuesta cambiar esa idea cuando, en el fondo, es la pura verdad.

-T: Así es y será, pero estamos intentando que esta idea te genere menos sufrimiento, que puedas vivir sin que te atormente esta idea. Inténtalo de nuevo, utilizando alguno de los pensamientos que hemos barajado con anterioridad.

Tras unos instantes en los que se le observaba un cambio en la expresión de la cara, con cierta resignación, refirió:

-P: Ya. He pensado que como no voy a poder librarme de ella, sólo me queda disfrutar todo lo que pueda día a día.

-T: ¿Te ha servido? ¿Ha ayudado a disminuir tu nivel de malestar emocional?

-P: Algo. 


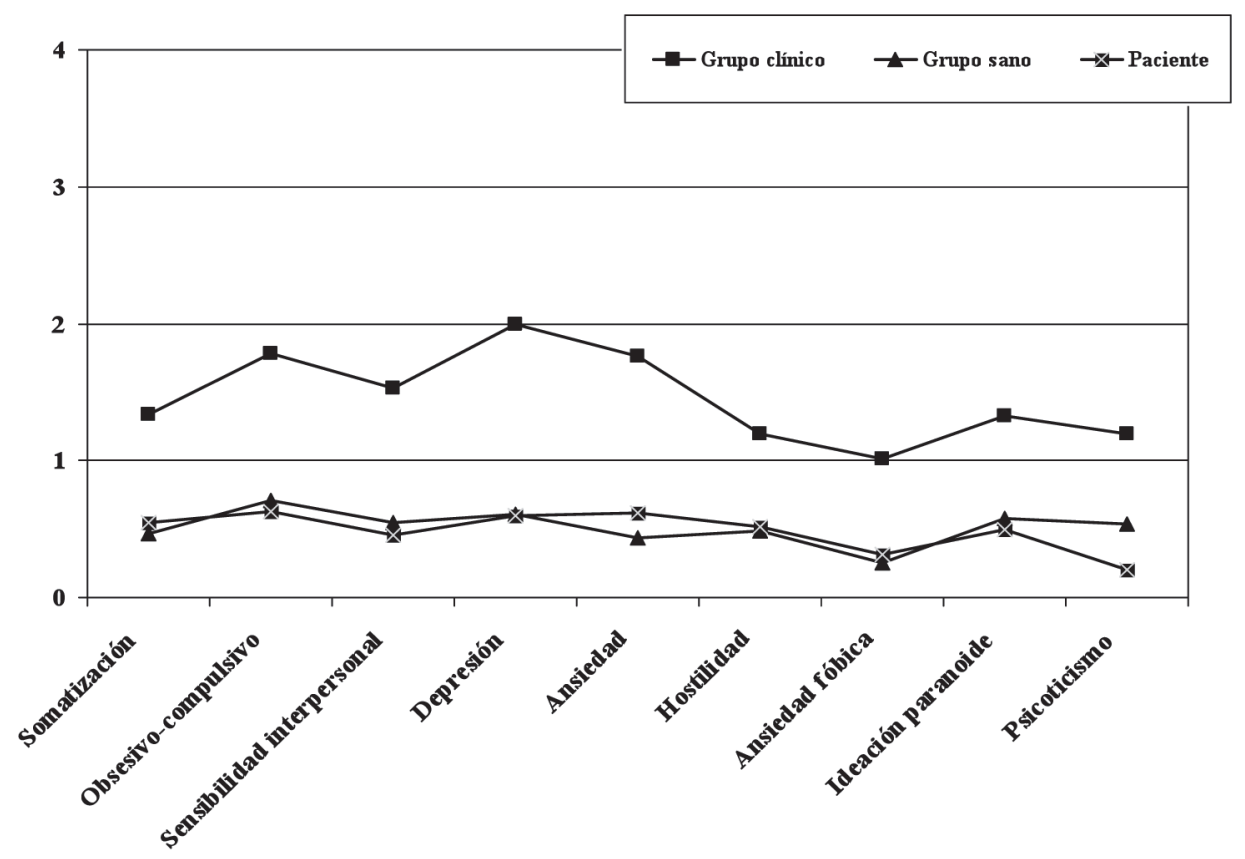

Figura 1. Puntuaciones obtenidas en el SCL-90-R por la paciente en la evaluación pretratamiento y los dos grupos de referencia extraídos de Bravo de Medina et al (2010).

-T: Algo, así es. Los cambios se suelen ir notando poco a poco.

\section{Análisis de los datos}

La presentación de los resultados se realiza en tres apartados:

1. Puntuaciones obtenidas en la evaluación pretratamiento en SCL-90-R, CL-FODS y conductas objetivo.

a) El Cuestionario de Evaluación de Síntomas - SCL-90-R.

Para determinar si el nivel de sintomatología psicopatológica en la paciente respondía en mayor medida al perfil de una persona de la población general o, por el contrario, se asemejaba al de una persona con un cuadro de ansiedad, se tomó como referencia el estudio Bravo de Medina et al. (2010) por su utilización con muestras de nuestro país.

Tal y como puede observarse en la Figura 1, las puntuaciones obtenidas por la paciente, en líneas generales, son más similares a las obtenidas por las participantes pertenecientes al grupo control sano (GCS) que del grupo control clínico (GCC) del citado estudio. Las mujeres del GCS no recibían tratamiento psiquiátrico ni psicológico mientras que las del GCC respondían en su mayoría a criterios de diagnóstico de trastorno de ansiedad.

b) La Escala de Ansiedad ante la Muerte CL-FODS.

Como puede observarse en la Tabla 6, en un número elevado de ítems (17 de 28) la puntuación dada es la máxima (5 puntos). En concreto, en relación con la propia muerte, aspectos tales como la total soledad de la muerte (item 1), todas las cosas que perderé al morir (ítem 3), cómo será el estar muerto (item 5), no poder pensar ni experimentar nada nunca más (ítems 6) y la desintegración del cuerpo después de morir (item 7) le generaban una ansiedad o preocupación máxima. Además, en relación 
Tabla 6

Puntuaciones de la paciente en la evaluación pretratamiento en la CL-FODS

Mucho

Nada

$\begin{array}{lllll}5 & 4 & 3 & 2 & 1\end{array}$

En relación a mi propia muerte

1. La total soledad de la muerte.

2. La brevedad de la vida (incertidumbre de cuándo será). ${ }^{(* *)}$

3. Todas las cosas que perderé al morir.

4. Morir joven.

5. Cómo será el estar muerto.

6. No poder pensar ni experimentar nada nunca más.

7. La desintegración del cuerpo después de morir.

$x$

$\begin{array}{ll} & \mathrm{x} \\ \mathrm{x} & \mathrm{x} \\ \mathrm{x} & \\ \mathrm{x} & \\ \mathrm{x} & \end{array}$

En relación a mi propio proceso de morir

8. La degeneración física que supone el proceso de morir.

9. El dolor que comporta el proceso de morir.

10. La degeneración mental del envejecimiento.

11. La pérdida de facultades durante el proceso de morir.

12. La incertidumbre sobre la valentía con que afrontaré el proceso de morir. (lucharé con todas las fuerzas) ${ }^{(* *)}$

13. La falta de control sobre el proceso de morir.

14. La posibilidad de morir en un hospital lejos de amigos y familiares.

En relación a la muerte de otros

15. La pérdida de una persona querida.

16. Tener que ver su cadáver.

17. No poder comunicarme nunca más con ella.

18. Lamentar no haberme llevado mejor con ella cuando aún estaba viva.

19. Envejecer solo, sin la persona querida.

20. Sentirme culpable por el alivio provocado por su muerte.

21. Sentirme solo sin ella.

En relación al proceso de morir de otros

22. Tener que estar con alguien que se está muriendo.

23. Tener que estar con alguien que quiere hablar de la muerte contigo.

24. Ver cómo sufre dolor.

25. Observar la degeneración física de su cuerpo.

26. No saber cómo gestionar tu dolor ante la pérdida de una persona querida.

27 Asistir al deterioro de sus facultades mentales.

28 Ser consciente de que algún día también vivirás esta experiencia.

$x$

$x$

$x$

$x$

$\mathrm{x}$

$x$

$x$

$x$

$x$

$x$

$\mathrm{x}$

$x$

$\mathrm{X}$

$\mathrm{X}$

$\mathrm{X}$

$\mathrm{X}$

$\mathrm{X}$

$\mathrm{x}$

$x$

$x$

\begin{tabular}{lcc}
\hline \multicolumn{1}{c}{ Puntuaciones } & Paciente & Estudio de Tomás-Sábado et al. (2007) ${ }^{(*)}$ \\
\hline En relación a mi propia muerte (rango 0 a 35) & 33 & 20,28 \\
En relación a mi propio proceso de morir (rango 0 a 35) & 26 & 25,71 \\
En relación a la muerte de otros (rango 0 a 35) & 22 & 27.42 \\
En relación al proceso de morir de otros (rango 0 a 10) & 30 & 24,95 \\
\hline
\end{tabular}

Nota. $\left.{ }^{*}\right)$ = puntuaciones medias de los participantes del estudio de Tomás-Sábado et al. $(2007) ;\left({ }^{* *}\right)=$ comentarios señalados por la paciente. 
con el propio proceso de morir, la degeneración física (item 8) y degeneración mental del envejecimiento (item 10), la pérdida de facultades durante el proceso (item 11) y el dolor que comporta (item 9), también le producían una ansiedad o preocupación máxima.

Por otro lado, en relación a la muerte de otros, la pérdida de una persona querida (ítem 15), tener que ver su cadáver (item 16) y no poder comunicarme nunca más con ella (item 17), así como en relación al proceso de morir de los otros, tener que estar con alguien que se está muriendo (item 22) o alguien que quiere hablar de la muerte (item 23), así como observar la degeneración física de su cuerpo (ítem 25) y el deterioro de sus facultades mentales (ítems 27), junto con ser consciente de que algún día también vivirás esta experiencia (ítem 28), también eran fuentes de preocupación o ansiedad máxima.

Paradójicamente, el modo de afrontamiento (lucharé con todas mis fuerzas, ítem 12), la percepción de control ante el proceso (item 13), el temor al lugar en que se producirá (item 14) o la soledad (ítems 19 y 20) o la culpabilidad ante la pérdida de alguien significativo (ítem 21) generaban una escasa preocupación o ansiedad en su vida, dado que adoptaba una actitud de lucha, como refleja el comentario señalado en el ítem 12 (ver Tabla 6).

En contraste con las puntuaciones obtenidas en el estudio de Tomás-Sábado et al. (2007), la paciente mostró un mayor nivel de ansiedad y preocupación en relación a la propia muerte (33 vs. 20,28$)$ y al proceso de morir de otros (30 vs. 24,95$)$, similar en relación al propio proceso de morir (26 vs. 25,71$)$ e inferior en relación a la muerte de otros (22 vs. 27,42). c) Grado de dificultad y frecuencia de evitación en las conductas objetivo en el pretratamiento.

Las conductas-objetivo se seleccionaron por la paciente. Se le sugirió que la elección de las mismas respondiera a los criterios siguientes: a) que le generaran en el momento presente un grado de dificultad medio-elevado por el malestar ocasionado, b) que se evitaran con frecuencia, c) que tuviera interés en realizarlas tras el tratamiento, $y \mathrm{~d}$ ) que fueran realistas, es decir, que pudieran llevarse a cabo con asiduidad y que formaran parte del contexto cotidiano de la paciente.

Tras estas indicaciones, se definieron seis conductas-objetivo. El nivel de dificultad y la frecuencia de evitación figuran en la Tabla 6.

Respecto al nivel de dificultad, como puede observarse, en las seis conductas-objetivo la puntuación mínima era de 8 puntos. Las puntuaciones más bajas constituían aquellas conductas relacionadas con el sentido de la vista. En concreto, mantener la vista ante una persona fallecida (cadáver) observada en la TV o en una revista y ver películas con la temática de la muerte. En ambas conductas, el control de la situación estaba en manos de la paciente $y$, por tanto, permitía decidir el nivel de implicación en la situación.

La puntuación más elevada correspondía a la conducta objetivo permanecer en la sala del tanatorio tras un fallecimiento. En esta conducta se encontraban inmersos prácticamente todos los sentidos en mayor o menor medida (oído, vista, olfato y tacto) y la percepción de control de la situación era, para ella, menor.

Respecto a la frecuencia de evitación, cabe destacar que la tendencia era evitar siempre. 
Tabla 7

Puntuaciones en la escala de conductas-objetivo en los distintos momentos de evaluación: pretratamiento, postratamiento y seguimientos al mes, a los seis y doce meses

\begin{tabular}{|c|c|c|c|c|c|c|}
\hline Conductas-objetivo & & Pret. & Post. & $\begin{array}{c}\text { Seg. } 1 \\
\text { mes }\end{array}$ & $\begin{array}{l}\text { Seg. } 6 \\
\text { meses }\end{array}$ & $\begin{array}{l}\text { Seg. } 12 \\
\text { meses }\end{array}$ \\
\hline \multirow{2}{*}{$\begin{array}{l}\text { 1. Mantener una conversación relacionada con el } \\
\text { acto y ritual del fallecimiento. }\end{array}$} & GM & 9 & 6 & 6 & 6 & 5 \\
\hline & $\mathrm{FE}$ & 5 & 2 & 3 & 2 & 2 \\
\hline \multirow{3}{*}{$\begin{array}{l}\text { 2. Permanecer en la sala del tanatorio tras un falle- } \\
\text { cimiento. }^{(*)}\end{array}$} & & $(8)$ & (4) & (5) & (4) & (4) \\
\hline & GIVI & 10 & 6 & 7 & 6 & 6 \\
\hline & $\mathrm{FE}$ & 4 & 4 & 4 & 3 & 3 \\
\hline \multirow[t]{2}{*}{ 3. Pasear por el cementerio, acompañada. } & GM & 9 & 5 & 5 & 4 & 4 \\
\hline & $\mathrm{FE}$ & 5 & 3 & 3 & 2 & 2 \\
\hline \multirow{2}{*}{$\begin{array}{l}\text { 4. Mantener la vista ante una persona fallecida (ca- } \\
\text { dáver) observada en TV o en una revista. }\end{array}$} & GM & 8 & 3 & 4 & 3 & 3 \\
\hline & $\mathrm{FE}$ & 5 & 2 & 3 & 2 & 2 \\
\hline \multirow{2}{*}{$\begin{array}{l}\text { 5. Tocar y/o coger objetos relacionados con el ri- } \\
\text { tual de la muerte. }\end{array}$} & GM & 9 & 5 & 5 & 3 & 3 \\
\hline & $\mathrm{FE}$ & 5 & 2 & 3 & 2 & 2 \\
\hline \multirow[t]{2}{*}{ 6. Ver películas con la temática de la muerte. } & GM & 8,5 & 4 & 4 & 4 & 3 \\
\hline & $\mathrm{FE}$ & 4 & 2 & 3 & 2 & 2 \\
\hline Grado de dificultad (rango 0-60) & & 53,5 & 28 & 30 & 26 & 24 \\
\hline Frecuencia de evitación (rango 0-30) & & 28 & 16 & 20 & 13 & 13 \\
\hline
\end{tabular}

Nota. $G M=$ grado de malestar $0=$ nada a $10=$ mucho); $F E=$ frecuencia de evitación $(0=$ nunca a $5=$ siempre).

$\left({ }^{*}\right)$ La puntuación dentro del paréntesis corresponde a la conducta objetivo "Permanecer en la sala del tanatorio tras un fallecimiento" sin ver el cadáver. No obstante, la puntuación total coincide con la valoración sin tener en cuanta esta opción.

No obstante, por la connotación de compromiso con los demás que tiene la conducta-objetivo permanecer en la sala del tanatorio tras un fallecimiento, en algunas ocasiones acudía, a pesar de la gran dificultad que le suponía.

En otras palabras, en la evaluación pretratamiento, como puede observarse en la Tabla 7, el nivel de dificultad para llevar a cabo las seis conductas-objetivo seleccionadas por la paciente era elevado: 53,5 puntos sobre un máximo de 60. Del mismo modo, la evitación de dichas conductas-objetivo se emitía con una frecuencia de casi siempre-siempre, con una puntuación de 28 sobre 30 puntos.

2. Datos obtenidos en la evaluación del seguimiento al año. a) Evolución del cambio en las medidas de ansiedad y preocupación ante la muerte: $\mathrm{CL}$ FODS

Como puede observarse en la Figura 2, en las cuatro subescalas de medida de ansiedad y preocupación ante la muerte, a partir de la CL-FODS, las puntuaciones habían disminuido en el seguimiento de los doce meses. Dicha reducción en las puntuaciones arroja una mejoría global del 38,92\%. Tomando en consideración cada una de las subescalas, en relación con la muerte de otros, la mejoría es del $45,45 \%$. En relación con la propia muerte y con el proceso de la muerte de otros, la mejoría asciende al 33,33\% y, finalmente, en relación con el propio proceso 


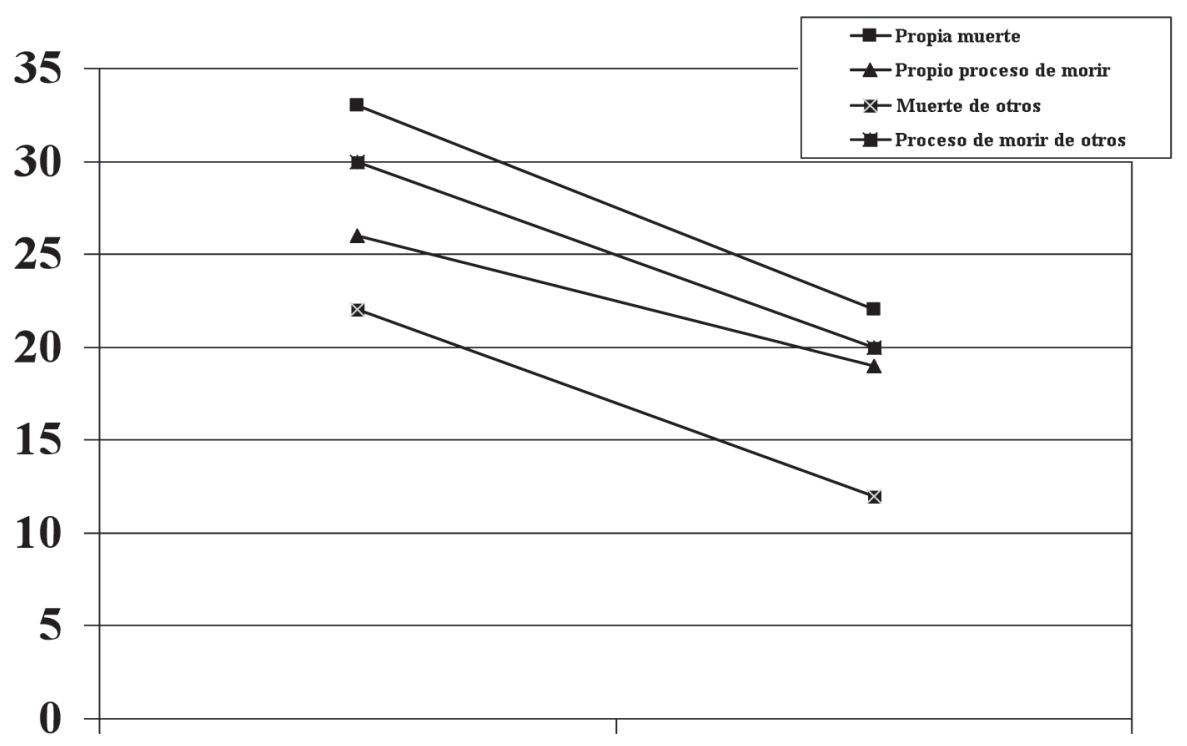

Pret.

Seg. 12 meses

Figura 2. Puntuaciones dadas en la CL-FODS por la paciente en la evaluación pretratamiento y en el seguimiento de 12 meses.

de morir, es del 26,92\%. Por tanto, y a pesar de producirse un cambio notable, tomando en consideración la diferencia entre uno mismo y el otro, el cambio en la ansiedad y preocupación ante la muerte de otros, pasado un año desde la intervención psicológica, era mayor a la ansiedad y preocupación experimentada ante la propia muerte, así como ante el proceso de morir, tanto de los otros como propio. En otras palabras, el camino hacia dejar de existir era la fuente de mayor malestar, más allá del acto de la muerte, especialmente cuando se refería a ella misma.

b) Evolución del cambio en las puntuaciones de la escala de conductas-objetivo en los distintos momentos de evaluación: pretratamiento, postratamiento y seguimientos al mes, seis y doce meses.

En la evaluación postratamiento, respecto al nivel de dificultad que oscilaba entre un rango de 0 a 60 puntos, como puede observarse en la Tabla 6, mientras que en la evaluación pretratamiento se obtenía una puntuación total de 53,5, en la evaluación postratamiento la puntuación total disminuía a 28 puntos.

Al analizar por separado, en las seis conductas-objetivo la puntuación mínima era de 3 puntos. De modo idéntico a la evaluación pretratamiento, las puntuaciones más bajas la conformaban aquellas conductas relacionadas con el sentido de la vista. En concreto, mantener la vista ante una persona fallecida (cadáver) observada en la TV o en una revista (3 puntos) y ver películas con la temática de la muerte (4 puntos). En ambas conductas, el control de la situación seguía estando en manos de la paciente $y$, por tanto, permitía decidir el nivel de implicación.

La puntuación más elevada correspondía a la conducta objetivo permanecer en la sala del tanatorio tras un fallecimiento (6 puntos). La percepción de control de la situación era menor. Algo similar sucedía con la conducta-objetivo mantener una conversación relacionada 
Tabla 8

Eficacia del tratamiento cognitivo-conductual a corto y largo plazo en la medida de conductas-objetivo

\begin{tabular}{|c|c|c|c|c|c|c|}
\hline \multirow[t]{2}{*}{ Conductas-objetivo } & \multicolumn{3}{|c|}{ Grado de dificultad } & \multicolumn{3}{|c|}{ Frecuencia de evitación } \\
\hline & $\begin{array}{l}\text { Mejoría tras el } \\
\text { tratamiento }{ }^{(1)}\end{array}$ & $\begin{array}{l}\text { Mantenimiento } \\
\text { de la mejoría }{ }^{(2)}\end{array}$ & $\begin{array}{l}\text { Eficacia del } \\
\text { tratamiento }^{(3)}\end{array}$ & $\begin{array}{c}\text { Mejoría tras el } \\
\text { tratamiento }\end{array}$ & $\begin{array}{c}\text { Mantenimiento } \\
\text { de la mejoría }\end{array}$ & $\begin{array}{l}\text { Eficacia del } \\
\text { tratamiento }\end{array}$ \\
\hline $\begin{array}{l}\text { 1. Mantener una con- } \\
\text { versación relaciona- } \\
\text { da con el acto y ritual } \\
\text { del fallecimiento. }\end{array}$ & $33,33 \%$ & $16,66 \%$ & $44,44 \%$ & $60 \%$ & $0 \%$ & $60 \%$ \\
\hline $\begin{array}{l}\text { 2. Permanecer en la } \\
\text { sala del tanatorio tras } \\
\text { un fallecimiento. }\end{array}$ & $40 \%$ & $0 \%$ & $40 \%$ & $0 \%$ & $50 \%$ & $50 \%$ \\
\hline $\begin{array}{l}\text { 3. Pasear por el ce- } \\
\text { menterio, acompa- } \\
\text { ñada. }\end{array}$ & $44,44 \%$ & $20 \%$ & $55,55 \%$ & $40 \%$ & $33,33 \%$ & $60 \%$ \\
\hline $\begin{array}{l}\text { 4. Mantener la vista } \\
\text { ante una persona } \\
\text { fallecida (cadáver) } \\
\text { observada en TV o en } \\
\text { una revista. }\end{array}$ & $62,5 \%$ & $0 \%$ & $62,5 \%$ & $60 \%$ & $0 \%$ & $60 \%$ \\
\hline $\begin{array}{l}\text { 5. Tocar y/o coger } \\
\text { objetos relacionados } \\
\text { con el ritual de la } \\
\text { muerte. }\end{array}$ & $44,44 \%$ & $40 \%$ & $66,67 \%$ & $40 \%$ & $0 \%$ & $40 \%$ \\
\hline $\begin{array}{l}\text { 6. Ver películas con } \\
\text { la temática de la } \\
\text { muerte. }\end{array}$ & 52,94 & $25 \%$ & $64,70 \%$ & $50 \%$ & $0 \%$ & $50 \%$ \\
\hline Total & $47,66 \%$ & $14,28 \%$ & $44,85 \%$ & $42,85 \%$ & $18,75 \%$ & $53,57 \%$ \\
\hline
\end{tabular}

Nota. ${ }^{(1)}$ Comparación Pretratamiento - Postratamiento; ${ }^{(2)}$ Comparación Postratamiento - Seguimiento de 12 meses; ${ }^{(3)}$ Comparación Pretratamiento -Seguimiento de 12 meses.

con el acto y ritual del fallecimiento (6 puntos), situación en la que la actitud de escucha y de intento de comprensión hacia la otra persona, junto al carácter no predecible del transcurso de una conversación, dificultaba el escape de la situación.

En la evaluación postratamiento, respecto a la frecuencia de evitación que oscila entre un rango de 0 a 30 puntos, como puede observarse en la Tabla 6 , mientras que en la evaluación pretratamiento se obtenía una puntuación total de 28 , en la evaluación postratamiento la puntuación total disminuía a 16 puntos.
Cabe destacar, tras las dieciséis sesiones de duración del tratamiento, que la tendencia era evitar entre casi nunca y a medias, excepto en la conducta-objetivo permanecer en la sala del tanatorio tras un fallecimiento, que tendía a evitar casi siempre.

En términos de mejoría tras el tratamiento, en la comparación pretratamiento-postratamiento, como puede observarse en la Tabla 6 , en las seis conductas-objetivo las puntuaciones correspondientes habían disminuido. Dicha reducción en las puntuaciones arroja 


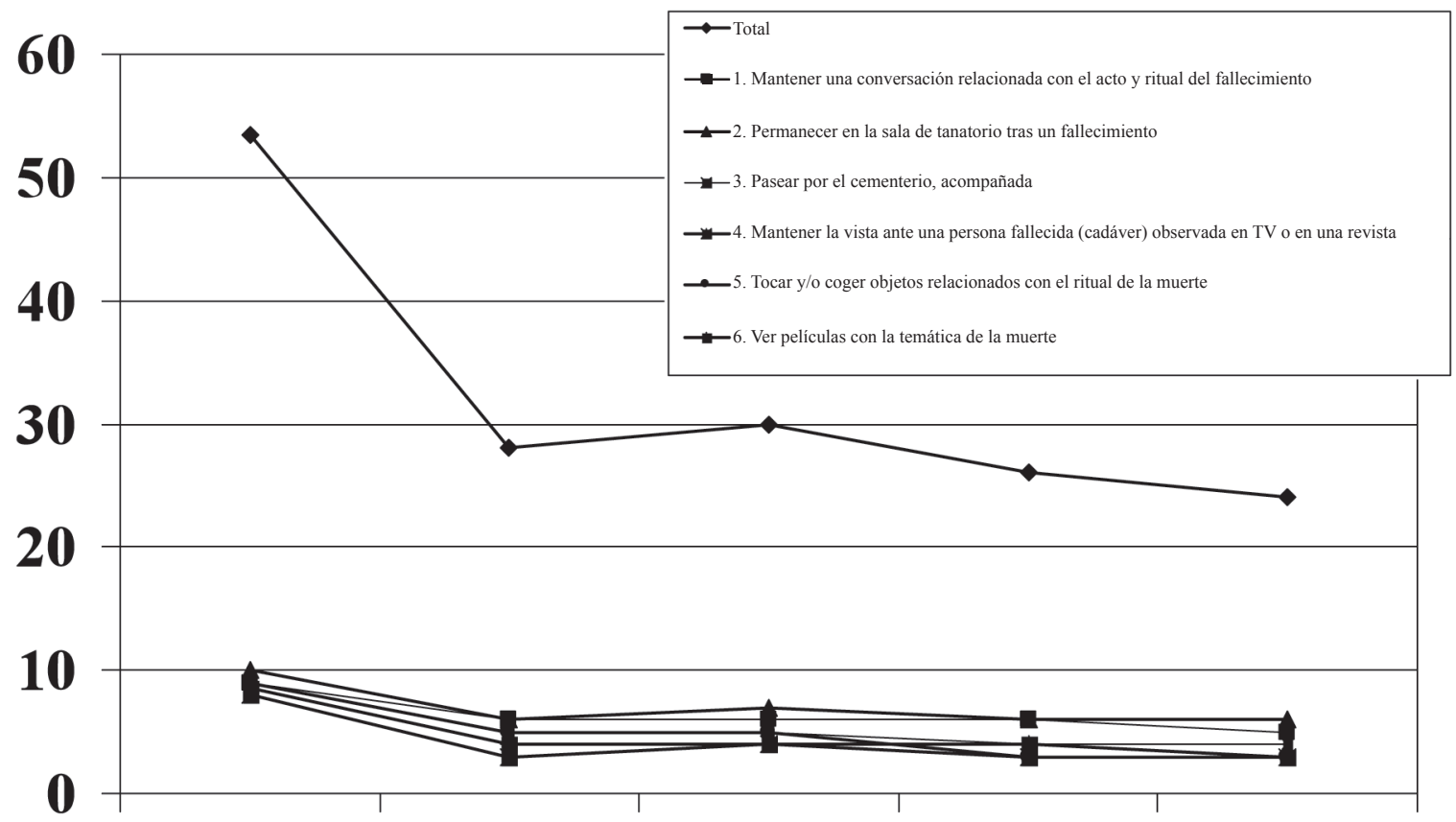

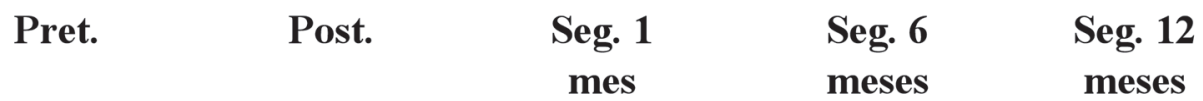

Figura 3a. Evolución del grado de dificultad en la escala de conductas-objetivo en los distintos momentos de evaluación.

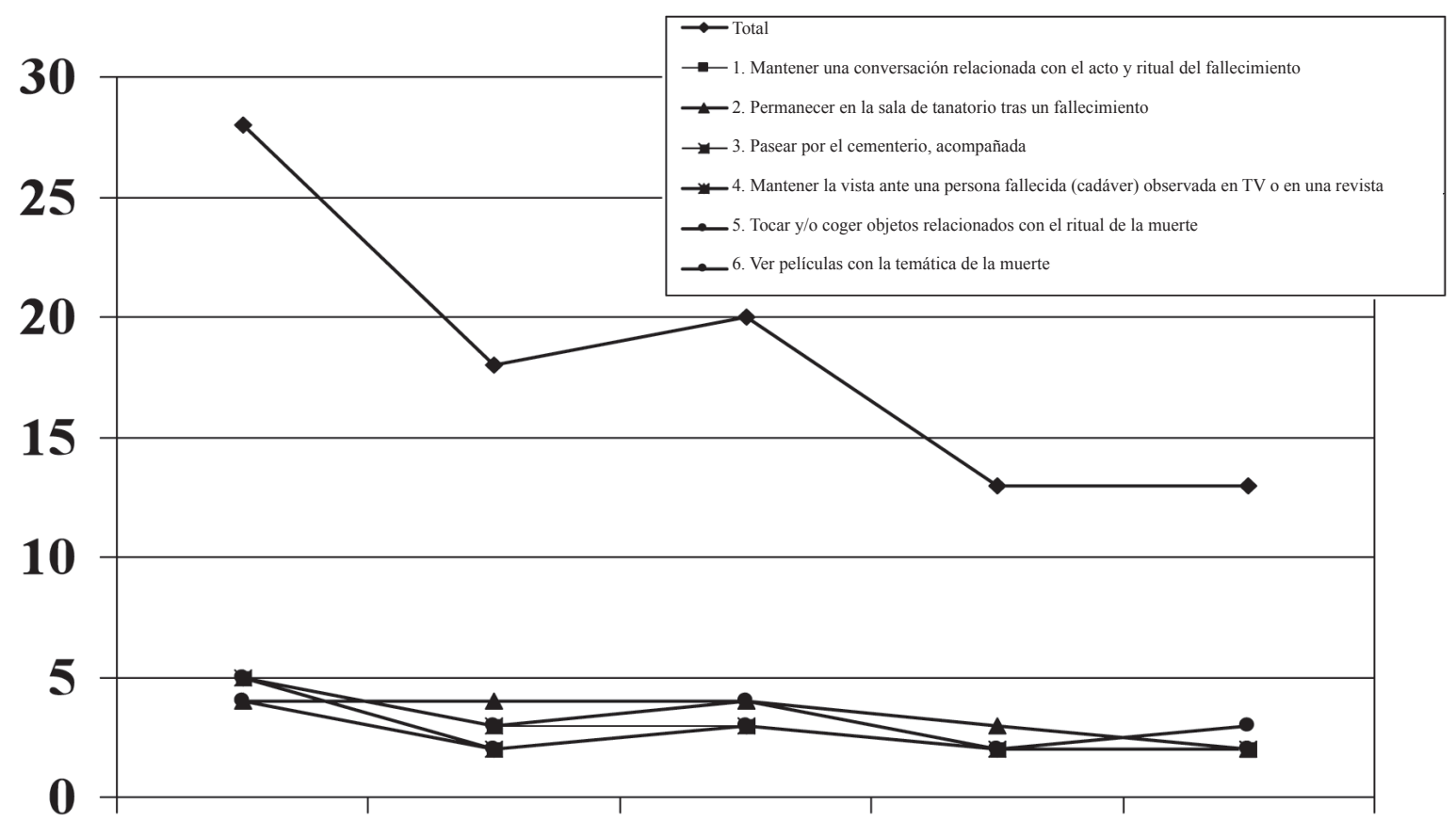
Pret.
Post.
Seg. 1
Seg. 6
Seg. 12
mes
meses
meses

Figura 3b. Evolución de la frecuencia de evitación en la escala de conductas-objetivo en los distintos momentos de evaluación. 
una mejoría global del $47,66 \%$ en el nivel de dificultad y del $42,85 \%$ en la frecuencia de evitación (Ver Tabla 8).

Tomando en consideración cada una de las conductas-objetivo, la mejoría en el nivel de dificultad oscila entre el $33,33 \%$ y el $62,5 \%$. La mejoría en la frecuencia de evitación oscila entre el $40 \%$ y el $60 \%$, excepto en la conductaobjetivo permanecer en la sala del tanatorio tras un fallecimiento. Por tanto, el cambio tras el tratamiento era notable en aquellas situaciones trabajadas específicamente, es decir, en las que se había ido exponiendo (en vivo y en imaginación) a la paciente al contexto tanatofóbico. Gráficamente, la evolución pre-postratamiento puede observarse en las Figuras $3 a$ y $3 b$.

Para determinar la efectividad de la intervención psicológica con el paso del tiempo, durante un año se llevaron a cabo tres evaluaciones de seguimiento: al mes, seis y doce meses.

Al cabo de un año desde la finalización del tratamiento, en la evaluación del seguimiento de doce meses se observó que el efecto del tratamiento tendía a mantenerse, e incluso se produjo una ligera mejoría tanto en el grado de dificultad $(14,28 \%)$ como en la frecuencia de evitación (18,75\%).

En otras palabras, en cuanto al nivel de dificultad, excepto en dos conductas-objetivo (permanecer en la sala del tanatorio tras un fallecimiento y mantener la vista ante una persona fallecida (cadáver) observada en TV o en una revista), en las otras cuatro el nivel de dificultad tiende a disminuir entre el 16,66\% (mantener una conversación relacionada con el acto y ritual del fallecimiento) y el $40 \%$ (tocar y/o coger obje- tos relacionados con el ritual de la muerte).

Como puede observarse en la Tabla 6, en el periodo entre la evaluación postratamiento y el seguimiento de un mes, es decir, en el intervalo de adquisición de la total responsabilidad de hacer frente al problema tras desvincularse de la ayuda profesional, se produjo un ligero aumento en las puntuaciones, tanto en el nivel de dificultad (10,3\%) como en la frecuencia de evitación (12,5\%). Posteriormente, a medio y largo plazo, estas puntuaciones tendieron a disminuir en la evaluación de los seis meses, con un mantenimiento de las mismas hasta la evaluación de los doce meses en la medida de frecuencia de evitación y continuando con una ligera disminución en las puntuaciones correspondientes a la medida de grado de dificultad. En otras palabras, la puesta en práctica de las estrategias terapéuticas adquiridas durante el tratamiento fue la clave para el mantenimiento de los beneficios adquiridos durante las dieciséis sesiones.

Finalmente, en la valoración sobre la eficacia de la aplicación del tratamiento cognitivoconductual en la paciente, se observa que la mejoría terapéutica se sitúa en el $44,85 \%$ en la medida de disminución del grado de dificultad y en el 53,57\% en la medida de reducción de la frecuencia de evitación en las conductas objetivo tanatofóbicas seleccionadas.

3. Valoración global de la paciente respecto al tratamiento recibido.

Se le solicitó que valorara la percepción de cambio ( 0 = nada a $5=$ muchísimo), señalando que había cambiado a "medias-bastante". Teniendo en cuenta que "no deseaba aceptar la 
muerte", sino aliviar el malestar asociado a ella, el balance fue "algo mejor".

\section{Discusión}

El objetivo del estudio de caso expuesto era valorar la eficacia de la terapia cognitivoconductual y, más en concreto, de las técnicas de exposición, en el tratamiento de la fobia a la muerte.

La paciente puede considerarse como una persona con unas características similares a la mayoría de la población, en cuanto a sintomatología se refiere, incluso en la medida de ansiedad. Esto se explicaría porque el contenido de los ítems de la dimensión de ansiedad del SCL-90-R explora síntomas de activación en general (nerviosismo, temblor, tensión, etc.), sin focalizarse en situaciones fóbicas concretas. En cambio, al recordar el perfil de respuesta que, a modo de ejemplo, se ha recogido en la Tabla 2 durante la observación directa, se comprueba que el nerviosismo e inquietud, la tensión, temblores y otros síntomas de activación general aparecen en la paciente ante situaciones tanatofóbicas.

Este tipo de síntomas son habituales en personas con fobia a la muerte, como reacción de lucha y/o huida ante la muerte, aun conociendo que es un hecho del que es imposible escapar puesto que la muerte siempre llega a todos (Yalom, 2008), pero la incertidumbre es cuándo. Por el contrario, en la medida en que el temor a la muerte esté asociado con la muerte propia (y más aún, con el temor a morir de un ataque de corazón), los síntomas que se manifiestan se aproximan a los de las crisis de pánico (taquicardias, mayor bombeo de sangre en la cabeza, presión en el pecho, etc.).

Ante la muerte y la constelación de elementos que la rodean (envejecimiento, deterioro, vacío, destrucción, desconocimiento, etc.), la paciente se percibe prácticamente sin capacidad de control. Por ello, utiliza como estrategias de afrontamiento, por un lado, el distanciamiento, la evitación conductual y cognitiva, en un intento de hacer llevadero el sufrimiento que le genera y, por otro lado, la lucha o resolución de cada situación que pudiera denotar una aproximación a la muerte (por ejemplo, se cuidaba la piel, el aspecto físico, leía y se mantenía activa, acudía a los reconocimientos médicos, etc.).

Un cierto temor a la muerte es habitual en la mayoría de las personas, miedo que se manifiesta, en ocasiones, con acciones tales como no querer sacar este tema, cuidar las palabras para no herir a los demás en momentos delicados, pero la interferencia en la vida cotidiana no suele alcanzar los niveles de esta paciente, hasta el extremo de experimentar crisis de ansiedad (tanto situacionales como anticipatorias) y evitar todo aquello relacionado con la muerte (Borda, 2008). Por ejemplo, las personas con fobia a la muerte se sienten incapaces de asistir a un accidentado -por temor a que esté muerto o agonizando-, donar un órgano -por temor a la desintegración- o a una transfusión. Las puntuaciones obtenidas en las subescalas de la CL-FODS indicaban que la paciente presentaba niveles elevados de ansiedad y preocupación por la muerte, superior a las participantes del estudio de Tomás-Sábado et al. (2007) llevado a cabo con profesionales del ámbito de la salud. Esta muestra sentía una mayor preocupación y/o ansiedad en relación 
con la muerte de otros, sin resultar sorprendente este resultado por su implicación con la salud de las personas.

Una actitud más frecuente, en cambio, es hablar de la muerte, de la aceptación de la muerte en el proceso del final de la vida (Wong \& Tomer, 2011). En esta etapa, tras pasar por periodos de negación, rechazo y desmoralización llega la aceptación del final de la vida, etapa en la que se busca la serenidad y el encuentro con uno mismo (García \& Barreto, 2008; Kübler-Ross, 2009). Pero en personas con fobia a la muerte, estas etapas se encuentran presentes con carácter permanente a lo largo de su vida. No pueden aceptarla y luchan ante cada situación hasta el final de su vida. Se sienten desesperadas al verse incompetentes para hacer frente a este problema.

La paciente, al final del tratamiento, seguía manteniendo que no quería aceptar la muerte. Su objetivo era aliviar el sufrimiento que le generaba. En otras palabras, hacer más llevadero el malestar que experimentaba. En este sentido, con el tratamiento propuesto se alcanza este objetivo con una mejoría importante.

Como conclusión, en el estudio de caso expuesto, el tratamiento se mostró eficaz: a) para reducir, en mayor medida, las conductas de evitación propuestas en las conductas-objetivo, b) para controlar los síntomas de ansiedad ante las distintas conductas-objetivo y otras situaciones, c) para controlarse ante la aparición y el mantenimiento de pensamientos y creencias relacionadas con la muerte, los muertos y el proceso de morir, y d) para disminuir el malestar psicológico asociado a la vivencia de la muerte. Al final de la relación terapéutica señaló que tendía a mantener (no evitar) los pensa- mientos y creencias abordadas en las sesiones así como a no evitar otros pensamientos automáticos no trabajados durante las sesiones.

Algunas consideraciones o limitaciones observadas son la existencia de una cierta dificultad para la generalización de la mejoría alcanzada a otras situaciones no trabajadas en las conductas objetivo y la baja o casi nula iniciativa propia para acercarse a situaciones tanatofóbicas. En este sentido, se propone unas sesiones de recordatorio cada cierto tiempo. Junto a esto, tal y como señalan Wong y Tomer (2011) acerca de la conveniencia de dialogar para aceptar la muerte, el tratamiento se centró en el componente fóbico, sin considerar otros componentes como por ejemplo, cultural o espiritual, aspectos este último de gran relevancia, por el carácter existencial que rodea al fenómeno de la muerte y el proceso de morir.

\section{Referencias}

American Psychiatric Association (2004). Manualestadísticodelostrastornosmentales. (DSM-IV-TR). Washington CD: Autor.

Avia, M. D. (1992). Exposición forzada, control respiratorio y manejo de respuestas agresivas en el tratamiento de un caso de tanatofobia reactivo a estrés postraumático. Análisis y Modificación de Conducta, 18, 27-35.

Bayés, R. (2006). Afrontando la vida, esperando la muerte. Madrid: Alianza.

Borda, M. (2008). Aportaciones al tema de la muerte desde la psicología clínica. VI Congreso de la Asociación Española de Psicología Clínica y Psicopatología. 27-29 noviembre. Huelva.

Bravo de Medina, R., Echeburúa, E., \& Aizpiri, J. (2010). Características psicopatológicas y 
dimensiones de personalidad en pacientes adultos jóvenes dependientes de cannabis en tratamiento: Un estudio comparativo. Adicciones, 22, 245-252.

Del Río, C. (2005). Guía de ética profesional en Psicología Clínica. Madrid: Pirámide.

Derogatis,L.R.,\&Cleary,P.A.(1977).Confirmation of the dimensional structure of the SCL-90: A study in construct validation. Journal of Clinical Psychology, 33, 981-989.

Foa, E., \& Wilson, R. (2001). Venza sus obsesiones. Un revolucionario método para liberarse de su comportamiento obsesivo. Barcelona: Robin Book.

García, G., \& Barreto, M.P. (2008). Trastornos del estado de ánimo al final de la vida: ¿Desmoralización o depresión?. Revista de Psicopatología y Psicología Clínica, 113, 123133.

González de Rivera, J.L., De las Cuevas, C., Rodríguez, M., \& Rodríguez, F. (2002), Cuestionario de 90 Síntomas SCL-90-R. Madrid:TEA.

Jacobson, E. (1939). Progressive relaxation. Chicago: University of Chicago Press.

Kübler-Ross. E. (2009). On death and dying. Abingdon, UK: Routledge. (Trabajo original publicado en 1969).

Lester, D. (1990). The Collett-Lester Fear of Death Scale: The original version and a revisión. Death Studies, 14, 451-468.
Montero, I., \& León, O.G. (2007). Guía para nombrar los estudios de investigación en Psicología. International Journal of Clinical and Health Psychology, 7, 847-862.

Robles, J. I., Andreu, J. M., \& Peña, M. E. (2002). SCL-90-R: Aplicación y análisis de sus propiedades psicométricas en una muestra de sujetosclínicosespañoles. Psicopatología Clínica, Legal y Forense, 2, 1-19.

Templer, D. I. (1970). The construction and validation of a Death Anxiety Scale. Journal of General Psychology, 82, 165-177.

Tomás-Sábado, J., Limonero, J. T., \& AbdelKhalek, A. M. (2007). Spanish Adaptation of the Collett-Lester Fear of Death Scale. Death Studies, 31, 249-260.

Tomer, A., Eliason, G. T., \& Wong, P. T. P. (2008). Existencial and spiritual issues in death attitudes. New York, NY: Lawrence Erlbaum Associates.

Virués-Ortega, J., \& Moreno-Rodríguez, R. (2008). Guidelines for clinical case reports in behavioral clinical Psychology. International Journal of Clinical and Health Psychology, 8, 765-777.

Yalom, I.D. (2008). Staring at thesun:Overcoming the terror of death. San Francisco, CA: JosseyBass.

Wong, P. T. P., \& Tomer, A. (2011). Beyond terror and denial: The positive psychology of death acceptance. Death Studies, 35, 99106. 